\title{
Is there a place in the United Kingdom for intensive antacid treatment for chronic peptic ulceration?
}

\author{
R FAIZALLAH, H A DE HAAN, N KRASNER, R J WALKER, A I MORRIS, M J CALAM, \\ D A BUDGETT
}

\begin{abstract}
Sixty nine patients with chronic duodenal or juxtapyloric ulceration were studied in a prospective double blind randomised trial to compare the efficacy of antacid and placebo at high $(30 \mathrm{ml}$ seven times daily) and $10 \mathrm{w}(10 \mathrm{ml}$ as required) doses. After four weeks ulcers had healed in 12 out of 18 patients $(67 \%)$ receiving "low dose" antacid compared with in six out of 17 patients $(35 \%)$ receiving low dose placebo; ulcers had also healed in six out of 19 patients (32\%) receiving "high dose" antacid compared with in two out of 15 patients $(13 \%)$ receiving high dose placebo. Overall, the effect of antacid was superior to that of placebo in healing ulcers $(p<0.05)$ and the effect of low dose treatment was superior to that of high dose treatment $(p<0.01)$. There were no significant differences between antacid and placebo at eight weeks. Antacid was better than placebo in relieving pain, but the difference was not significant. Poor compliance and high incidence of diarrhoea made high dose antacid an impractical treatment. Low dose antacid was associated with a significantly better rate of healing than high dose antacid and was far better tolerated.

This low dosage of antacid should be considered to be an active treatment in trials of ulcer healing.
\end{abstract}

Walton Hospital, Liverpool L9 1AE

R FAIZALLAH, MB, MRCP, registrar

H A DE HAAN, MB, FRCS, clinical assistant

N KRASNER, MD, FRCP, consultant gastroenterologist

R J WALKER, MD, FRCP, consultant gastroenterologist

A I MORRIS, MD, MRCP, senior lecturer, department of medicine, University of Liverpool

M J CALAM, MD, MRCP, registrar

ICI Pharmaceuticals Division, ICI, Cheshire

D A BUDGETT, MA, MSC, statistician

Correspondence to: Dr A I Morris.

\section{Introduction}

In Great Britain an estimated $£ 30000000$ is spent annually on antacids, for which over 50 formulations are listed in Mims. Although the lay public and medical practitioners traditionally accept that these compounds have beneficial therapeutic effects, the evidence is controversial. ${ }^{2}$ Most published clinical trials assessing the effectiveness of antacid treatment in accelerating the healing of chronic peptic ulceration may be criticised because of poor study design, ${ }^{3}$ and results from the placebo controlled randomised studies contradict each other. Peterson et al, comparing a four week intensive regimen of liquid antacid with placebo in 74 patients, showed enhanced healing of duodenal ulcers in a group treated with antacid. ${ }^{4}$ In contrast, Hollander and Harlan did not find any significant difference between 27 patients treated with antacid tablets taken hourly over four weeks and 23 patients taking placebo. ${ }^{\circ}$

Proof of the effects of antacids in relieving pain is also inconclusive. Lawrence, and Rune and Zachariassen, found liquid antacid to be more effective than placebo. ${ }^{6}{ }^{7}$ Littman et al produced conflicting results comparing aluminium hydroxide gels with placebo, ${ }^{8}$ and Sturdevant et al found that identical pain relief could be achieved with large quantities of either antacids or placebo. ${ }^{\circ}$

In the United States of America frequent high doses of antacids have been shown to be as effective as treatment with cimetidine in healing duodenal ulcers. ${ }^{1011}$ In Europe, however, antacids are usually prescribed less often and in much lower doses despite the paucity of data showing that such a regimen may be effective. We therefore conducted a randomised double blind placebo controlled trial of different antacid regimens in the treatment of chronic duodenal ulcer.

\section{Patients and methods}

Patients referred to the gastrointestinal unit at this hospital during the study with symptoms suggestive of peptic ulcer disease and found to be eligible were admitted to the trial. All showed evidence on endoscopy of chronic active duodenal or juxtapyloric ulceration; juxtapyloric ulceration was confirmed histologically as being benign. The trial was approved by the hospital ethical committee. After 
patients had given their informed written consent treatment was started with the trial drug within 24 hours after endoscopy. Nonambulant patients, those with actively bleeding ulcers or serious concurrent systemic diseases, those who had been treated with compounds known to heal ulcers within the preceding month, and those who had ingested ulcerogenic agents within one week before the trial were excluded. Patients were randomly allocated with equal probability to one of four regimens of treatment-namely, (1) $30 \mathrm{ml}$ antacid one and three hours after meals and before retiring at night (high dose antacid); (2) $30 \mathrm{ml}$ placebo one and three hours after meals and before retiring at night (high dose placebo); (3) $10 \mathrm{ml}$ antacid as required for relief of ulcer pain (low dose antacid); (4) $10 \mathrm{ml}$ placebo as required for relief of ulcer pain (low dose placebo).

In the event of intractable adverse effects patients were allowed to modify the treatment doses and the change was recorded on their treatment cards. The antacid used was a magnesium hydroxide plus aluminium hydroxide liquid preparation containing activated dimethicone (Antasil, Stuart Pharmaceuticals, Cheshire) with a high in vitro neutralising capacity $(10 \mathrm{ml} \simeq 50 \mathrm{mmol})$. The placebo was a liquid formulation that looked and tasted identical to the antacid and did not have any buffering capacity. In addition, all groups were offered $500 \mathrm{mg}$ paracetamol tablets (BPC) with instructions to take two tablets whenever the need arose for additional relief from ulcer pain (maximum of $4 \mathrm{~g} /$ day). Patients were asked not to change their smoking or drinking habits during the trial. All drugs taken in addition to the trial drugs were recorded.

The study was conducted double blind. Experienced endoscopists at this hospital repeated fibreoptic endoscopy, while the patient was sedated with diazepam, after four weeks of treatment and, if the ulcer was found to be incompletely healed, again at eight weeks. Initially the size of the ulcer was determined by reference to open biopsy forceps placed directly on the crater of the ulcer; a healed ulcer was defined as complete re-epithelialisation of the entire surface mucosa. Patients were interviewed every two weeks, and the frequency and duration of ulcer pain together with the volume of liquid drug, number of paracetamol tablets, and details of side effects were recorded according to daily entries patients made on their treatment cards. Routine haematological and biochemical laboratory tests were performed on entry and every four weeks throughout the study.

\section{Results}

Sixty nine patients with a mean age of 44.5 (range 18-69) years were entered over 18 months. Fourteen $(20 \%)$ were women, $26(38 \%)$ were non-smokers, and $15(21 \%)$ did not drink alcohol. The mean alcohol consumption was $43.9 \mathrm{~g}$ alcohol/day (range 0-386 $\mathrm{g}$ alcohol/ day). The four treatment groups were comparable with respect to demography and potential prognostic factors.

Table I shows the results of treatment with the different regimens after four and eight weeks. By using a logistic model for the fitting of proportion (see addendum) for statistical analysis, at four weeks antacid proved to be superior to placebo $(p<0.05)$ and the low dose regimen superior to the high dose regimen $(p<0.01)$ (table II). At eight weeks the differences were no longer significant.

TABLE I-Results of treatment with four regimens in patients with peptic ulcer

\begin{tabular}{|c|c|c|c|c|}
\hline & \multicolumn{2}{|c|}{$\begin{array}{c}\text { No }(\%) \text { patients receiving } \\
\text { high dose: }\end{array}$} & \multicolumn{2}{|c|}{$\begin{array}{c}\text { No }(\%) \text { patients receiving } \\
\text { low dose: }\end{array}$} \\
\hline & $\begin{array}{l}\text { Antacid } \\
(\mathbf{n}=19)\end{array}$ & $\begin{array}{l}\text { Placebo } \\
(n=15)\end{array}$ & $\begin{array}{l}\text { Antacid } \\
(\mathrm{n}=18)\end{array}$ & $\begin{array}{l}\text { Placebo } \\
(\mathrm{n}=17)\end{array}$ \\
\hline $\begin{array}{l}\text { Ulcer healed at four weeks } \\
\text { Ulcer healed at eight weeks }\end{array}$ & $\begin{array}{r}6(32) \\
10(53)\end{array}$ & $\begin{array}{l}2(13) \\
7(46)\end{array}$ & $\begin{array}{l}12(67) \\
14(78)\end{array}$ & $\begin{array}{l}6(35) \\
9(53)\end{array}$ \\
\hline
\end{tabular}

Pain was an insensitive discriminant function of ulcer presence. Fifteen $(22 \%)$ of the patients had been asymptomatic during the two weeks preceding entry to the trial. Fifteen (36\%) and $11(38 \%)$ patients who, at four and eight weeks respectively, had unhealed ulcers had been free from pain for at least two weeks. Compared with placebo treatment, fewer patients in each group receiving antacid experienced pain during the trial. The difference, though suggestive, did not reach significance (table III). The number of paracetamol tablets taken by any of the groups was insufficient for statistical comparison, but there were no obvious differences.

\section{COMPLIANCE AND SIDE EFFECTS}

Patients randomised to treatment with antacid at a high dose were expected to consume $2940 \mathrm{ml}$ of the drug each fortnight ( 98 doses), but in every case they consumed considerably less of the drug than the equivalent placebo group and even the placebo groups consumed less than expected by roughly $1000 \mathrm{ml} /$ fortnight ( 33 doses) (table IV).

TABLE II-Statistical analysis of ulcer healing, comparing antacid with placebo at high and low doses using the Generalised Linear Interactive Modelling computer program

\begin{tabular}{lcc}
\hline \multicolumn{1}{c}{ Effect } & $\begin{array}{c}\chi^{2} \\
\left(\mathrm{df}^{2}=1\right)\end{array}$ & $\mathrm{p}$ \\
\hline \multicolumn{3}{c}{ Four weeks' } \\
treatment \\
Treatment & 4.16 & $<0.05^{*}$ \\
Dose & 6.76 & $<0.01 \dagger$ \\
Non-additivety & 0.03 & $\mathrm{NS}$ \\
\multicolumn{4}{c}{ Eight weeks' treatment } \\
Treatment & 1.6 & $\mathrm{NS}$ \\
Dose & 1.96 & $\mathrm{NS}$ \\
Non-additivety & 0.8 & $\mathrm{NS}$ \\
\hline
\end{tabular}

*Antacid better.

tLow dose better.

TABLE III-Pain experienced by patients with peptic ulcers during treatment with antacid or placebo*

\begin{tabular}{|c|c|c|c|c|}
\hline \multirow{2}{*}{$\begin{array}{c}\text { Time } \\
\text { (weeks) }\end{array}$} & \multicolumn{2}{|c|}{ Patients receiving antacid } & \multicolumn{2}{|c|}{ Patients receiving placebo } \\
\hline & Total No & $\begin{array}{l}\text { No (\%) with } \\
\text { ulcer pain }\end{array}$ & Total No & $\begin{array}{l}\text { No (\%) with } \\
\text { ulcer pain }\end{array}$ \\
\hline \multicolumn{5}{|c|}{ Drug given at high dose } \\
\hline $\begin{array}{l}0 \\
2 \\
4 \\
6 \\
8\end{array}$ & $\begin{array}{r}19 \\
14 \\
14 \\
5 \\
7\end{array}$ & $\begin{array}{r}12(63) \\
8(57) \\
3(21) \\
1(20) \\
3(43)\end{array}$ & $\begin{array}{r}15 \\
13 \\
11 \\
9 \\
10\end{array}$ & $\begin{array}{r}11(73) \\
11(85) \\
7(64) \\
7(78) \\
4(40)\end{array}$ \\
\hline \multicolumn{5}{|c|}{ Drug given at low dose } \\
\hline $\begin{array}{l}0 \\
2 \\
4 \\
6 \\
8\end{array}$ & $\begin{array}{r}18 \\
14 \\
16 \\
2 \\
2\end{array}$ & $\begin{array}{c}14(78) \\
10(71) \\
8(50) \\
2(100) \\
2(100)\end{array}$ & $\begin{array}{r}17 \\
17 \\
16 \\
9 \\
7\end{array}$ & $\begin{array}{l}15(88) \\
17(100) \\
11(69) \\
7(78) \\
6(86)\end{array}$ \\
\hline
\end{tabular}
* Significance of difference between treatment groups calculated using Fisher's
exact probability $\times 4$ to allow for multiple test. Differences were not significant at any stage.

TABLE IV-Median volumes of trial drugs consumed every two weeks

\begin{tabular}{ccc}
\hline $\begin{array}{c}\text { Duration of treatment } \\
\text { (weeks) }\end{array}$ & $\begin{array}{c}\text { Antacid } \\
(\mathrm{ml})\end{array}$ & $\begin{array}{c}\text { Placebo } \\
(\mathrm{ml})\end{array}$ \\
\hline \multicolumn{3}{c}{ Drugs given at high dose } \\
2 & 1050 & 1950 \\
4 & 1450 & 1675 \\
6 & 1500 & 1950 \\
8 & 525 & 2100 \\
\multicolumn{4}{c}{ Drugs given at low dose } \\
2 & 350 & 300 \\
4 & 300 & 125 \\
6 & 210 & 300 \\
8 & 300 & 200 \\
\hline
\end{tabular}

In cases where adverse reactions were not the factor limiting the dose poor compliance was generally attributed by the patients to the inconvenience of frequent dosing despite the availability of pocket size $(30 \mathrm{ml})$ bottles for use during working hours. There were no differences in treatment compliance between the two groups receiving drugs at a low dose, both consuming roughly $250 \mathrm{ml} /$ fortnight ( 25 doses) (table IV).

Five patients $(16 \%)$ receiving placebo compared with none treated with antacid withdrew from the study prematurely because they considered the treatment to be ineffective. One patient $(0.9 \%)$ treated with placebo was withdrawn because of bleeding. The major 
cause of poor compliance with treatment was considerable drug induced diarrhoea. Seventeen $(89 \%)$ and $16(86 \%)$ of the patients receiving high dose antacid had diarrhoea at two and four weeks respectively compared with seven $(23 \%)(p<0.001)$ and six $(20 \%)$ $(p<0.01)$ of all patients receiving placebo. No other clinical adverse reactions related to the drug were observed. No temporal or drug related abnormalities in haematology or serum biochemistry were noted in any treatment group during the trial.

\section{Discussion}

In this double blind trial the natural rate of healing of chronic peptic ulcer was $25 \%$ in four weeks, rising to $49 \%$ in eight weeks. This finding supports the conclusion of others that ulcers appear to heal much more slowly in patients in the United Kingdom than elsewhere. ${ }^{12-14}$ As expected, antacid produced significantly better rates of healing than placebo. Surprisingly, however, antacid given at a low dose was superior to antacid given at a high dose. That such a regimen might be effective in ulcer healing had been suggested by large multicentre trials in the USA, in which the patients receiving placebo, who were allowed to take liquid antacid as required for relief of symptoms, did as well as a group treated with cimetidine. This finding adds a new concept to peptic ulcer treatment.15 16 The reason for the effectiveness of small doses of antacid remains obscure. The lack of demonstrable increased benefit with the more intensive antacid regimen was probably due to the considerable underdosing in this group. A single large dose of antacid ( $30 \mathrm{ml}$ aluminium hydroxide) has been shown to increase postprandial secretion of gastric acid, ${ }^{17}$ presumably due to a decrease in the $\mathrm{pH}$ dependent feedback inhibition of gastrin release. ${ }^{18}$ Such a dose of antacid taken by patients allocated to the high dose regimen at bed time might have exaggerated this effect. Perhaps higher doses of antacids taken more frequently ( $>210 \mathrm{ml}$ daily) would more continuously neutralise the excess acid produced and enhance the healing of the ulcer. Such doses were, however, found to be unacceptable to our patients.

As the minimum effective dose of antacid has not been defined in this study our findings have implications for other comparative trials of ulcer healing in which the efficacy of new treatments are evaluated. If effects on ulcer healing of new treatments are not to be distorted the exclusion of concurrent treatment with antacid should be mandatory.

As expected, there was a consistent trend in favour of more rapid healing in patients with a short history of peptic ulcer disease. Smoking did not appear to have a detrimental effect.

Our results suggest that frequent large doses of antacids may have reduced the incidence, frequency, and duration of ulcer pain more effectively than intermittent smaller doses (table III). Even in patients receiving placebo ulcer pain tended to diminish relative to time, but, as shown by others, ${ }^{9}$ there was unequivocal evidence of a rapid placebo related effect during single episodes of pain. Our placebo contained a silicone polymer that, although having no neutralising capacity, might have contributed to the relief of dyspeptic symptoms by virtue of its antifoaming or antiflatulant activity. We tried, however, to record only characteristic ulcer pain, against which our placebo was considered to be inert. Inadequate relief from pain was severe enough to precipitate dropout or withdrawal from the trial only in patients receiving placebo, and paracetamol, prescribed as an alternative treatment, did not appear to represent a satisfactory substitute for antacid in these instances.

Our patients did not find acceptable the intensive high dose regimens advocated in the USA. ${ }^{1011}$ Despite our enthusiastic attempts at persuasion, patient compliance was as problematical as described by Roth and Berger. ${ }^{10}$ The median volume of high dose placebo consumed was only about two thirds the desired amount (table IV). Significantly less high dose antacid was taken than had been recommended, and several patients either dropped out or refused to continue treatment because of diarrhoea despite adjustments in dose and our choice of a trial antacid containing aluminium hydroxide. The low dose antacid regimen was far better tolerated. Sixteen patients $(87 \%)$ receiving low dose antacid completed the entire course of treatment compared with $12(61 \%)$ of those receiving high dose antacid and $14(82 \%)$ and $12(80 \%)$ of those receiving low dose and high dose placebo respectively.

Thus this study has shown clearly, and for the first time, that the large doses of antacid advocated in the USA are poorly tolerated by patients in Liverpool; this might apply to the United Kingdom as a whole. Treatment with low doses $(10 \mathrm{ml}$ as required) of antacid can significantly enhance ulcer healing, and is superior to treatment with high doses of antacid and far better tolerated. The pain relieving effect of antacid was not significantly better than that of placebo. In trials of ulcer healing results must be interpreted with caution if self administration of antacids is permitted.

We thank Sister E C Smith and the nursing and pharmacy staff at this hospital for their help with this trial. We also thank Stuart Pharmaceuticals, Cheshire, for supplying the trial material and Mr M C K Tweedie and Mr C R West, Biostatistic Unit, Liverpool University, for their additional help in the statistical analysis.

\section{Addendum}

The $\chi^{2}$ values were obtained as follows: if $\hat{\mathbf{p}}$ is the estimated proportion of healing

$$
\operatorname{Logit}(\hat{\mathbf{p}})=\log \frac{(\hat{\mathbf{p}})}{1-\mathbf{p}}=\mu+\alpha_{i}+\beta_{j}+\gamma_{i j}
$$

where $\mathrm{i}$ (compound) $=1,2$ (antacid, placebo), $\mathrm{j}($ dose $)=1,2$ (low, high), $\mu=$ grand mean, $\alpha=$ variable depending on compound, $\beta=1$, variable depending on dose, and $\gamma=$ interaction between compound and dose.

The $\chi^{2}$ values are those corresponding to twice the improvement in log likelihood (corresponding to fitting $\alpha, \beta$, and $\gamma$ respectively, a statistic that has roughly a $\chi^{2}$ distribution). The calculation was done using the Generalised Linear Interactive Modelling (GLIM) computer program.

\section{References}

1 Anonymous. Antacids for duodenal ulcer [Editorial]. Br Med f 1981;282:1495-6. 2 Morris T, Rhodes J. Progress report: antacids and peptic ulcer-a reappraisal. Gut 1979;20:538-45.

3 Christensen E, Juhl E, Tygstrup N. Treatment of duodenal ulcer. Randomised trials of a decade, 1964-74. Gastroenterology 1977;73:1170-8.

4 Peterson WL, Sturdevant RAL, Frankl HD, et al. Healing of duodenal ulcer with an antacid regimen. $N$ Engl f Med 1977;297:341-5.

5 Hollander $\mathrm{D}$, Harlan $\mathrm{J}$. Antacids vs placebos in peptic ulcer therapy. $\mathcal{F} A M A$ 1973;226:1181-5.

6 Lawrence JS. Dietetic and other methods in the treatment of peptic ulcer.

Lancet $1952 ; \mathrm{i}: 482-5$.
7 Rune SJ, Zachariassen A. Acute relief of epigastric pain by antacid in duodenal ulcer patients. Scand f Gastroenterol [Suppl] 1979;14:41-5.

8 Littman A, Welch R, Fruin RC, Aronson AR. Controlled trials of aluminium hydroxide gels for peptic ulcer. Gastroenterology 1977;73:6-10.
turdevant RAL, Isenberg JI, Secrist D, Ansfield J. Antacid and placebo produced similar pain relief in duodenal ulcer patients. Gastroenterology produced simil $1977 ; 72: 1-5$.

10 Ippoliti AF, Sturdevant RAL, Isenberg JI, et al. Cimetidine versus intensive antacid therapy for duodenal ulcer. Gastroenterology 1978;74:393-5.

11 Ippoliti A, Elashof J, Valenzuela $J$, et al. Recurrent ulcer after successful treatment with cimetidine or antacid. Gastroenterology 1983;85:875-81.

12 Peter P, Gonvers JJ, Pelloni S, et al. Cimetidine in the treatment of duodenal ulcer. In: Creutzfeldt W, ed. Cimetidine: proceedings of an international symposium on histamine $\mathrm{H}_{2}$-receptor antagonists. Amsterdam: Excerpta Medica, 1978 $190-8$

13 Langman MJS. Treatment trials and their design. Clin Gastroenterol 1978;7:

14 Bardhan $\mathrm{KD}$. Cimetidine in duodenal ulceration. In: Wastell $\mathrm{C}$, Lance $\mathrm{P}$, eds. Cimetidine: the Westminster Hospital symposium. Edinburgh: Churchil Cimetidine: the Westming, 1978:31-56.

15 Fordtran JS. Placebos, antacids and cimetidine for duodenal ulcer. N Englf Med 1978;2:8:1081-3.

16 Binder $\mathrm{HJ}$, Cocco A, Crossley RJ, et al. Cimetidine in the treatment of duodenal ulcer: a multicentre double blind study. Gastroenterology 1978;74:380-8.

17 Deering TB, Carlson GL, Malagelorda JR, et al. Fate of oral neutralizing antacid and its effects on post prandial gastric secretion and emptying. Gastroenterology and its efrects on

18 Walsh JH, Richardson CT, Fordtran TS. pH dependence of antacid secretion and gastrin release in normal and ulcer subjects. $\mathcal{F}$ Clin Invest 1975;55:462-8.

19 Roth HP, Berger DG. Studies on patient co-operation in ulcer treatment.
Gastroenterology 1960;38:630-9.

(Accepted 28 fuly 1984) 